\title{
A Framework for Assessing the Social Impact of Interdependencies in Digital Business Ecosystems
}

\author{
Prince Kwame Senyo ${ }^{1,2}$ [0000-0001-7126-3826], Kecheng Liu ${ }^{2}$ and John Effah ${ }^{1}$ \\ ${ }^{1}$ Department of Operations and Management Information Systems, University of Ghana \\ Business School, Ghana \\ ${ }^{2}$ Informatics Research Centre, Henley Business School, University of Reading, Reading, \\ United Kingdom \\ \{pksenyo, jeffah\}@ug.edu.gh, k. liu@henley.ac.uk
}

\begin{abstract}
As digital technology continues to pervade many organisations, new collaborative models such as digital business ecosystems (DBEs) emerge. DBE is a socio-technical network of digital platforms, processes, individuals and organisations from different industries that collectively create value. In DBEs, participants interdepend on each other and technology platforms to develop individual capabilities required to deliver value to end-users. Notwithstanding the benefits of DBE, a key challenge for focal partners is how to assess the social impact of the various interdependencies. Social impact refers to the social effect of interdependencies on DBE participants. More often, the focus has been on assessing the operational impact of interdependencies while limited attention has been paid to the social perspective. However, we argue that the social impact of interdependencies is equally important since it can significantly affect value cocreation. In this study, we develop a framework to help focal partners assess the social impact of interdependencies in DBEs. An empirical case study of a port DBE is used to illustrate our framework.
\end{abstract}

Keywords: Digital Business Ecosystem (DBE), Interdependence Assessment, Social Impact Assessment, Organisational Semiotics, Framework

\section{Introduction}

Organisations are forming strategic alliances beyond their traditional industry boundaries to collectively create greater value. As such, new collaborative value creation webs such as digital business ecosystems (DBEs) have emerged. DBE is a socio-technical network of digital platforms, processes, individuals and organisations from different industries that collectively create value [7]. DBE platforms offer participants opportunities to develop individual innovations that serve as inputs in value co-creation. At the core of DBE are complex interdependencies between entities such as technology platforms, processes, individuals and organisations.

Interdependence refers to an interaction between entities such as processes [2], organisations [14] and technologies [1]. These interactions create a network of interdependencies that influence value co-creation, effectiveness and resilience of DBEs. As 
a result, for focal DBE partners, it is extremely important to understand the impact of the various interdependencies. However, due to multiple DBE interdependencies, this ideal understanding is difficult to obtain [8]. Thus, there is a need for systematic approaches to assess the impact of DBE interdependencies, especially from the social perspective.

There have been some approaches to assess interdependencies such as interdependence pattern measurement [8], interdependence process assessment [2], technology interdependence measurement [1] and interdependence profitability assessment [5]. However, per our knowledge, no study has accounted for the social impact of interdependencies in DBEs. We define social impact as the social effect of interdependencies on DBE participants $[3,11]$. For instance, the effect of a new interdependence on someone's job security could be referred to as a social impact of the interdependence. In recent times, calls have been made for expansion in the scope of assessment approaches to consider social factors $[6,13]$. In addressing some of these calls, this study develops a framework to assess the social impact of interdependencies in DBEs.

The rest of this paper is structured as follows. Section 2 presents the background and related works on DBE, interdependence impact assessment approaches and social impact effects. Next, Section 3 presents the proposed framework while Section 4 illustrates its application in a vehicle clearing domain of Ghana's main port, Tema Harbour hereafter referred to as Ghana's port DBE. Section 5 concludes the paper with implications for research and practice.

\section{Background and Related Works}

\subsection{Digital Business Ecosystem}

DBE is an internet driven socio-technical environment that focuses on collective value creation between diverse entities [12]. Typically, DBEs are characterised by complex interdependencies between organisations and individuals, technology platforms and processes that cut across industry boundaries. With these interdependencies come conflict of norms, values, beliefs and strategies due to diversity of participants. In some cases, the perception of stakeholders about an interdependence may affect their productivity [6]. Indeed, there may be resistance and sometimes sabotage from stakeholders if they feel unease about the impact of some interdependencies. Thus, it is important to constantly assess the impact of interdependencies to address conflicts that may affect productivity.

Though there have been some studies on DBE, a key aspect such as interdependence assessment is still under-researched. In the extant information systems literature, some studies have focused on providing a foundational understanding of DBE by explicating definitions, origin and characteristics [7, 12]. Alternatively, some DBE studies also focus on platforms [15], capability development [9], system integration [4], and norm evolution [10]. Notwithstanding the contributions from these studies, a critical area like social impact assessment of DBE interdependence is still open and less researched. 
Hence, the need for further studies to consolidate understanding and support development of DBE.

\subsection{Interdependence Impact Assessment Approaches}

Although there is a paucity of approaches for interdependence assessment in general, a few exceptions exist [e.g., 1, 5, 8]. For instance, Pentland et al. [8] present an approach conceptualised as "interdependence thermometer" that transforms digital trace data into networks to visualize and measure patterns of routine interdependencies. The findings reveal that using artefacts to evaluate interdependence enables better understanding and visualising of relationships that are intuitively difficult to comprehend. In another strand, Bailey et al. [1] proposed the "technology gap" approach to understand how two groups of engineers traverse interdependencies between technologies during their course of work. The findings reveal that the first group of engineers built automated data transfer process to address technology interdependencies gaps while the others allowed the gaps to exist, resulting in delays.

While these insights from the existing approaches are important, some limitations still exist. First, the extant approaches focus on measuring patterns of interdependence while understanding of the social impact of these interdependencies remains limited. Second, the existing approaches have largely assessed interdependencies at the organisational level [5] while limited understanding exists at the DBE level. Given the current pace at which DBEs are emerging across organisational boundaries, it is only prudent to develop approaches that align with this new collaborative network.

\subsection{Social Effects of Interdependencies in DBEs}

From organisational semiotics, social effect refers to conditions that influence people's perception of a situation [11]. For instance, social effects may have an impact on people's well-being, values and norms. In the extant information systems literature, social effects have not been largely accounted for in prior interdependence assessment approaches, calls have been made $[6,13]$ for this consideration as these effects may influence people's productivity. In some cases, the perception of individuals about an effect may create fear and resistance to undertake certain activities. As a result, this may negatively affect how they undertake their work. In this study, we draw on Hall's [3] 10 social dimensions as the foundation for our proposed social impact assessment framework. Table 1 presents the 10 social dimensions and their description. 
Table 1. Ten social dimensions [3, 13]

\begin{tabular}{|c|c|}
\hline Aspects & Description \\
\hline Association & $\begin{array}{l}\text { Grouping, alliances e.g., the formation of teams to evoke com- } \\
\text { petitiveness and sense of belonging of participants }\end{array}$ \\
\hline Subsistence & $\begin{array}{l}\text { Physical and economic matters related to existences e.g., im- } \\
\text { pact of an interdependence on income or job security }\end{array}$ \\
\hline Classification & $\begin{array}{l}\text { Differentiation of people by gender, age, level of education } \\
\text { e.g. whether an interdependence improves equal opportunity } \\
\text { for all }\end{array}$ \\
\hline Territoriality & $\begin{array}{l}\text { Accessibility e.g., the impact of an interdependence may lead } \\
\text { to an erosion of control, influence, or loss of authority }\end{array}$ \\
\hline Temporality & $\begin{array}{l}\text { Time division, synchronous, asynchronous e.g. issues of time } \\
\text { zone differences caused by an interdependence }\end{array}$ \\
\hline Learning & $\begin{array}{l}\text { Sharing knowledge, gaining awareness e.g., de-skill or more } \\
\text { opportunity for learning new skills within an interdependence }\end{array}$ \\
\hline Recreation & $\begin{array}{l}\text { Fulfilment, joy e.g., whether the job becomes more interest- } \\
\text { ing or boring within an interdependence }\end{array}$ \\
\hline Protection & $\begin{array}{l}\text { Fairness, rights e.g., granting file rights access to the appro- } \\
\text { priate groups of people and maintain the confidentiality of in- } \\
\text { formation }\end{array}$ \\
\hline Exploitation & $\begin{array}{l}\text { Individual's vs organisation's interests e.g., cutbacks on oper- } \\
\text { ating costs with salary-cut, retrenchment or longer working } \\
\text { hours }\end{array}$ \\
\hline Interaction & $\begin{array}{l}\text { Interrelations and communications, e.g., fostering collabora- } \\
\text { tive attitudes in the workplace }\end{array}$ \\
\hline
\end{tabular}

\section{Framework for assessing the social impact of DBE interdependencies}

This section presents our proposed framework to assess the social impact of DBE interdependencies. The framework as presented in Figure 1 has three main components, namely: (1) DBE context articulation, (2) interdependence profiling and (3) interdependence social impact assessment. These components as discussed below iteratively depict inherent steps to assess the social impact of DBE interdependencies. 


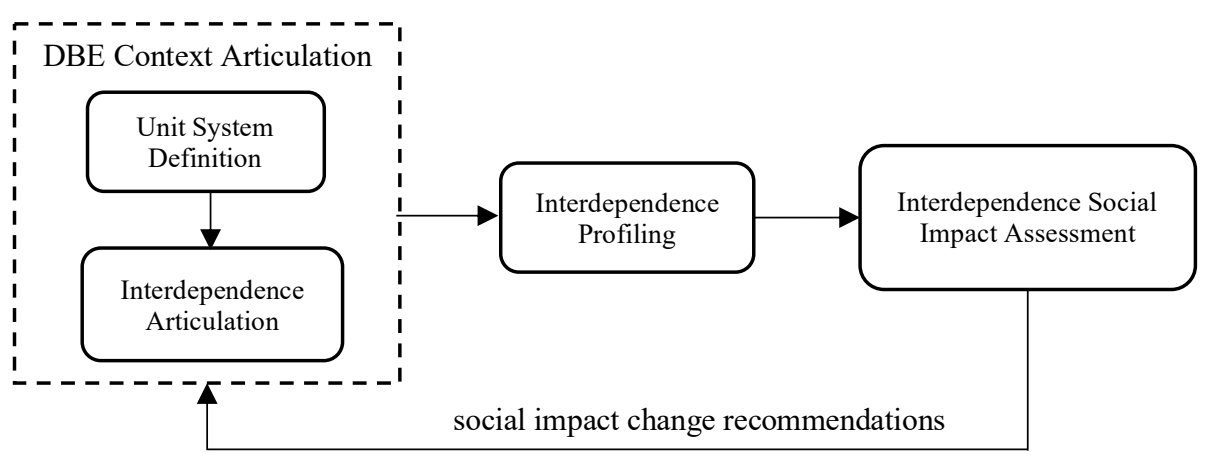

Fig. 1. DBE framework for assessing the social impact of interdependencies

DBE Context Articulation. This component establishes the setting for the interdependence social impact assessment. Typically, a DBE involves several relationships. As a result, it is important to clearly delineate the scope to evaluate. This component consists of two approaches - unit system definition and interdependence articulation. The unit system definition enables articulation of subsystems in a domain. The unit system definition as presented in Figure 2 involves identification and examination of the various subsystems in a domain through observation, review of standard operating procedures and interactions with participants. The main elements of the unit systems definition are date, unit system ID, version of analysis, unit system name, description as well as sub-unit systems involved.

\begin{tabular}{|l|l|l|}
\hline Date: & Unit system ID: & Version No: \\
\hline Unit System Name & & \\
\hline Unit System Description & & \\
\hline Sub-Unit Systems & & \\
\hline
\end{tabular}

Fig. 2. Unit system definition approach

After defining the unit systems in a DBE, the various interdependencies are articulated. We propose an interdependence articulation approach (See Fig. 3) to aid this process. The independence articulation approach supports the identification of the various interdependencies in a unit system. The main elements of the approach are unit system, interdependence ID and name as well as DBE entities involved in an interdependence. Interdependence articulation can be undertaken by observation, review of standard operating procedures and interaction with relevant stakeholders.

\begin{tabular}{|l|l|l|l|}
\hline Unit System & Interdependence ID & Interdependence Name & Entities Involved \\
\hline & & & \\
\hline
\end{tabular}

Fig. 3. Interdependence articulation approach

Interdependence profiling. This component derives relevant information on interdependencies needed to conduct the social impact assessment. Figure 4 shows the 
interdependence profiling approach and details its elements, namely interdependence ID, date, version number, name, description, outcome, business processes, as well as entities involved. The ID is a unique identifier for interdependencies while date and version details the period and number of analysis iterations undertaken respectively. The interdependence description details what an interdependence entails while the outcome presents the goal of an interdependence. The business processes depict series of actions to accomplish an interdependence. Lastly, the entities involved in an interdependence are listed with their respective responsibilities.

\begin{tabular}{|c|c|c|c|}
\hline \multirow{2}{*}{\multicolumn{4}{|c|}{$\begin{array}{l}\text { Interdependence ID: } \\
\text { Interdependence Name: }\end{array}$}} \\
\hline & & & \\
\hline \multicolumn{4}{|c|}{ Interdependence Description: } \\
\hline \multicolumn{4}{|c|}{ Interdependence Outcome: } \\
\hline \multicolumn{4}{|l|}{ Business Processes: } \\
\hline Entities Involved & Entity & Responsibility & \\
\hline
\end{tabular}

Fig. 4. Interdependence profiling approach

Interdependence social impact assessment. This last component measures and provides results on the social impact of interdependencies in a DBE. The social impact assessment determines the perception of partners in relation to interdependencies they participate in and how these interdependencies affect their ultimate productivity. We draw on Hall's [3] 10 social dimensions as criteria for the social impact assessment. Figure 5 shows the social impact assessment approach that articulates how stakeholders perceive interdependencies in a DBE.

\begin{tabular}{|c|c|c|c|c|c|}
\hline Interdependencies & INT1 & INT2 & INT3 & INT...n & \\
\hline Dimensions & Partner 1 & Partner 2 & Partner 3 & Partner...n & $C_{j}=\sum_{i=1}^{10} V i j$ \\
\hline Subsistence & & & & & \\
\hline Classification & & & & & \\
\hline Territoriality & & & & & \\
\hline Temporality & & & & & \\
\hline Learning & & & & & \\
\hline Recreation & & & & & \\
\hline Protection & & & & & \\
\hline Exploitation & & & & & \\
\hline Association & & & & & \\
\hline Interaction & & & & & \\
\hline$S_{i}=\sum_{i=1}^{n} V i j$ & & & & & \\
\hline
\end{tabular}

Fig. 5. Social impact assessment approach

Each partners' perception is assessed with a positive and negative scale where +3 and -3 represent the most positive and negative impacts respectively with respect to their interdependencies. At the end, the total scores are aggregated based on the two 
equations below to determine the overall perception of partners on the social impact of interdependencies.

$$
C_{j}=\sum_{i=1}^{10} V i j
$$

where $\mathrm{C} j$ is the total score of all partners on an interdependence (e.g. INT1) by aspect $i$

$$
S_{i}=\sum_{j=1}^{n} V i j
$$

where $\mathrm{S}$ is the total score of the impact of the 10-social dimensions assessed by partner $j ; n$ is the total number of partners

\section{Case Study: Ghana's port digital business ecosystem}

To illustrate the applicability of our framework, we used Ghana's port DBE as a case study. We selected this case because it provides an empirical instantiation of a DBE, featuring characteristics of complex interdependencies between diverse participants from different industries, technology platforms and processes. Ghana is an African country bordered by the Gulf of Guinea and the Atlantic Ocean to the South. As such, some landlocked countries heavily utilise Ghana's ports as a transit point. The key partners in the port are the Ghana Ports and Harbours Authority (GPHA), the Customs Division of the Ghana Revenue Authority (hereafter referred to as Customs), shipping lines, scanner operators, freight forwarders, terminal operators, Government Ministries, Departments and Agencies as well as importers and exporters.

To illustrate our framework, we present a high-level generic vehicle clearing process as follows: 1) Importer relies on the electronic ministries, departments and agencies (eMDA) platform to obtain unique consignment reference (UCR), 2) Importer relies on the e-MDA platform to submit import declaration form (IDF), 3) Importer depends on the Pre-Arrival Assessment Reporting System (PAARS) to apply for Customs Classification and Valuation Report (CCVR), 4) Customs valuation officers use the PAARS to process application for CCVR, 5) Importer uses the Ghana Customs Management Systems (GCMS) to submits Customs declaration, 6) Customs compliance officers process declaration using the GCMS, 7) Importer relies on the bank to make duty and other charges payment, 8) Importer uses the Ghana Integrated Cargo Clearance System (GICCS) to make request for shipping release, 9) Customs examination officers use GCMS to release vehicle after physical examination and 10) Importer relies on the Driver and Vehicle Licensing Authority (DVLA) for temporary number plate. For this study, four separate set of questionnaires were designed in conjunction with Hall's 10 social dimensions for data collection. Data were collected from each group of partners in the interdependencies. This is because different groups of partners are involved in each interdependence in the vehicle clearing process.

Using our framework (see Figure 1), the result of the unit system definition in Ghana's port DBE is presented in Figure 6. From the case, Ghana's port DBE can be 
decomposed into many unit systems. As established earlier, our focus is the vehicle clearing domain, so we identified this as the unit system (U1) of concern. From the analysis, U1 is composed of four sub-unit systems represented as U1.1 to U1.4 which can also be further decomposed to lower granularity if necessary.

\begin{tabular}{|l|l|l|}
\hline Date: 17/1/2018 & Unit system ID: $\mathbf{U}_{\mathbf{1}}$ & Version: 1.0 \\
\hline Unit System Name & $<<$ Vehicle Clearing Unit System $>>$ & \\
\hline $\begin{array}{l}\text { Unit System } \\
\text { Description }\end{array}$ & This unit system covers activities involved in clearing vehicles at Ghana's port. \\
\hline Sub-Unit Systems & $\begin{array}{l}\text { U1.1 Import declaration processing, } \mathrm{U}_{1.2} \text { Duty and taxes payment, } \mathrm{U}_{1.3} \text { Physical } \\
\text { examination and } \mathrm{U}_{1.4} \text { Vehicle release processing }\end{array}$ \\
\hline
\end{tabular}

Fig. 6. Unit system definition in Ghana's port DBE

Next, we articulate interdependencies in the unit system defined (U1). Using the interdependence articulation approach, we identified 10 interdependencies in the unit system. Figure 7 shows the unit system, interdependencies articulated as well as entities involved.

\begin{tabular}{|c|c|c|c|}
\hline Unit System & ID & Interdependence Name & Entities Involved \\
\hline \multirow{10}{*}{$\begin{array}{l}\mathrm{U}_{1} \\
<<\text { vehicle } \\
\text { clearing } \\
\text { domain }>>\end{array}$} & INT1 & $\begin{array}{l}\text { Importer relies on the e-MDA platform to obtain UCR } \\
\text { online }\end{array}$ & $\begin{array}{ll} & \text { Importer } \\
\text { - } & \text { E-MDA } \\
\end{array}$ \\
\hline & INT2 & Importer relies on the e-MDA platform to submit IDF & $\begin{array}{ll}\text { - } & \text { Importer } \\
\text { - } & \text { E-MDA } \\
\end{array}$ \\
\hline & INT3 & Importer depends on the PAARS to apply for CCVR & $\begin{array}{ll}\text { - } & \text { Importer } \\
\text { - } & \text { PAARS } \\
\end{array}$ \\
\hline & INT4 & $\begin{array}{l}\text { Customs valuation officers use the PAARS platform to } \\
\text { process CCVR online }\end{array}$ & $\begin{array}{ll}\text { - } & \text { Customs } \\
\text { - } & \text { PAARS } \\
\end{array}$ \\
\hline & INT5 & $\begin{array}{l}\text { Importer uses the GCMS to submits Customs declara- } \\
\text { tion }\end{array}$ & $\begin{array}{ll}\text { - } & \text { GCMS } \\
\text { - } & \text { Importer } \\
\end{array}$ \\
\hline & INT6 & $\begin{array}{l}\text { Customs compliance officers process declaration us- } \\
\text { ing the GCMS }\end{array}$ & $\begin{array}{ll}\text { - } & \text { Customs } \\
\text { - } & \text { GCMS } \\
\end{array}$ \\
\hline & INT7 & $\begin{array}{l}\text { Importer relies on the bank to make duty and other } \\
\text { charges payment }\end{array}$ & $\begin{array}{l}\text { - Importer } \\
\text { - Bank } \\
\end{array}$ \\
\hline & INT8 & $\begin{array}{l}\text { Importer uses the GICCS to make shipping release re- } \\
\text { quest }\end{array}$ & $\begin{array}{ll}\text { - } & \text { GICCS } \\
\text { - } & \text { Importer }\end{array}$ \\
\hline & INT9 & $\begin{array}{l}\text { Customs examination officers use GCMS to release a } \\
\text { vehicle after a physical examination }\end{array}$ & $\begin{array}{ll}\text { - } & \text { Customs } \\
\text { - } & \text { GCMS } \\
\end{array}$ \\
\hline & INT10 & Importer relies on DVLA for temporary number plate & $\begin{array}{l}\text { - Importer } \\
\text { - DVLA }\end{array}$ \\
\hline
\end{tabular}

Fig. 7. Interdependence articulation from $U_{1}$ of Ghana's port DBE

Based on the second component of our framework, we perform interdependence profiling on our case study. The aim of interdependence profiling is to analyse the interdependencies articulated in the unit system (U1) so that more information can be derived to enable the social impact assessment. Figure 8 shows a sample interdependence profile detailing information on the description, outcome, business processes, entities involved as well as their responsibilities.

\begin{tabular}{|l|l|l|}
\hline Interdependence ID: INT3 & Date: 5/07/2017 & Version No:1 \\
\hline
\end{tabular}




\begin{tabular}{|c|c|c|}
\hline \multicolumn{3}{|c|}{$\begin{array}{l}\text { Interdependence Name: Importer depends on the PAARS to apply for CCVR } \\
\text { Interdependence Description: This interdependence supports the importer to apply for CCVR using } \\
\text { PAARS }\end{array}$} \\
\hline \multicolumn{3}{|c|}{ Interdependence Outcome: Enables successful, timely and cost-efficient CCVR processing } \\
\hline \multicolumn{3}{|c|}{$\begin{array}{l}\text { Business Processes: } \\
\text { - } \quad \text { Importer submits vehicle clearing application to Customs through PAARS } \\
\text { - } \quad \text { Customs performs classification and valuation and generates CCVR } \\
\text { - } \quad \text { Customs issues an electronic copy of CCVR to the importer and sends a copy to GCMS }\end{array}$} \\
\hline \multirow{3}{*}{$\begin{array}{l}\text { Entities } \\
\text { Involved }\end{array}$} & Entity & Responsibility \\
\hline & Importer & Submits CCVR application through PAARS \\
\hline & PAARS & $\begin{array}{l}\text { PAARS allows the importer to submit an application if all necessary require- } \\
\text { ments are met }\end{array}$ \\
\hline
\end{tabular}

Fig. 8. Independence profiling

Lastly, we perform the social impact assessment on the interdependencies identified in the vehicle clearing unit system. For all the interdependencies identified, we first compute the average score for each interdependence based on the ten social dimensions. Second, we aggregate the score for each social dimension in respect of each interdependence horizontally and vertically using equation (1) and (2) above. Figure 9 shows the social impact scores of the various interdependencies on the ten social dimensions.

\begin{tabular}{|l|l|l|l|l|l|l|l|l|l|l|l|}
\hline & $\begin{array}{l}\text { INT } \\
\mathbf{1}\end{array}$ & $\begin{array}{l}\text { INT } \\
\text { Dimensions }\end{array}$ & $\begin{array}{l}\text { INT } \\
\mathbf{3}\end{array}$ & $\begin{array}{l}\text { INT } \\
\mathbf{4}\end{array}$ & $\begin{array}{l}\text { INT } \\
\mathbf{5}\end{array}$ & $\begin{array}{l}\text { INT } \\
\mathbf{6}\end{array}$ & $\begin{array}{l}\text { INT } \\
\mathbf{7}\end{array}$ & $\begin{array}{l}\text { INT } \\
\mathbf{8}\end{array}$ & $\begin{array}{l}\text { INT } \\
\mathbf{9}\end{array}$ & $\begin{array}{l}\text { INT } \\
\mathbf{1 0}\end{array}$ & $\boldsymbol{C}_{\boldsymbol{j}}=\sum_{\boldsymbol{i}=1}^{\mathbf{1 0}} \boldsymbol{V}_{\boldsymbol{i j}}$ \\
\hline Subsistence & 1 & 3 & 2 & 1 & 2 & 2 & 3 & -1 & 1 & -1 & 13 \\
\hline Classification & 2 & 2 & 1 & 0 & 2 & 2 & 1 & 0 & 3 & 0 & 13 \\
\hline Territoriality & 3 & 2 & 2 & 0 & 3 & -1 & -1 & -1 & 1 & -3 & 5 \\
\hline Temporality & -1 & 0 & 2 & -2 & 0 & 2 & -1 & 1 & 0 & -1 & 0 \\
\hline Learning & 0 & 1 & 2 & 1 & 1 & 2 & -1 & -1 & -1 & -2 & 2 \\
\hline Recreation & 0 & 2 & 2 & 0 & 2 & 1 & 1 & -1 & 2 & -2 & 7 \\
\hline Protection & 2 & 2 & 2 & 1 & 2 & 2 & 0 & 0 & 2 & -1 & 12 \\
\hline Exploitation & -2 & -1 & 0 & -2 & 0 & 2 & 0 & -1 & 0 & -1 & -5 \\
\hline Association & 1 & 1 & 1 & -1 & 1 & 1 & 0 & -1 & 0 & -1 & 2 \\
\hline Interaction & 0 & 2 & 1 & 0 & 2 & 2 & 0 & 0 & -2 & -1 & 4 \\
\hline$S_{i}=\sum_{j=1}^{n} V i j$ & 6 & 14 & 15 & -2 & 15 & 15 & 2 & -5 & 6 & -13 & \\
\hline
\end{tabular}

Fig. 9. Interdependence impact scores of the vehicle clearing unit system

From the results, interdependencies INT 3, 5 and 6 have the most positive impact scores (15) in the vehicle clearing domain U1. Conversely, interdependencies INT 10, 8 and 4 have the most negative impact scores $(-13,-5$ and 2$)$ respectively. For instance, the importers in interdependence INT 10 perceived it to have the lowest negative impact. This negative impact score can be explained by the face-to-face interactions involved in the interdependence. Importers require fast processes as delays may result in more operational cost. However, this interdependence requires importers to queue at DVLA's office to purchase a temporary number plate to move vehicles from the port. This manual process results in delays, favouritism and corruption. As such, importers view this interdependence as a hindrance to effective and efficient processes in vehicle clearing.

On the ten social dimensions, the results show that subsistence and classification aspects had the highest impact on interdependencies in U1. This can be explained by the perception of partners on the limited threat of job security of these interdependencies. Currently, the laws in Ghana's port DBE protects jobs of most key participants, 
hence the positive attitude regarding the social impact of interdependencies in U1. The limited discrimination in the port can be attributed to high process automation, thereby reducing face-to-face interaction in most interdependencies. Conversely, the exploitation, temporality, learning and association aspects recorded the lowest impact scores respectively. This result can be attributed to the presence of some loopholes in some interdependencies where importers are exploited. Also, in the current clearing processes, most activities are undertaken during the day, hence the low temporality impact score. At present, the clearing procedure offers limited avenues to learn new skills due to the routine nature of processes, hence the low impact score. Lastly, the low association score can be explained by digitalisation of many processes, leading to limited collaboration among partner groups.

In sum, we argue that critical attention is needed on interdependencies INT 10, 8, 4 and 7 since their social impact scores might negatively affect ultimate productivity of the unit system. Similarly, more attention should be paid to exploitation, temporality, learning, interaction and association aspects of interdependencies in the unit system as these have all recorded awful social impact scores. However, attempts should be made to improve on other interdependencies and social dimensions that recorded reasonable social impact scores.

\section{Discussion and Conclusion}

This study developed a framework to assess the social impact of interdependencies in DBEs since limited attention has been paid to the effect of social factors in prior approaches [e.g., 1, 5, 8]. The case illustration above demonstrates how our framework offers mechanisms to assess the social impact of interdependencies taking into consideration multiple perceptions of partners in a DBE. Using our framework, we successfully articulate a DBE's context, interdependencies and their social impacts. From our results, it is evident that interdependencies that involve face-to-face interactions recorded low social impact scores as they are largely characterised by corruption, extortion and delays. Conversely, interdependencies that occur via technology platforms recorded high social impact scores.

By providing a framework and demonstrating how to assess the social impact of interdependencies of a DBE, our study makes contributions to research and practice. From research perspective, this study brings new theoretical inspiration to DBE research through our framework and application of organisational semiotics principles. In addition, we contribute to research by applying Hall's social dimensions in two new domains - DBE and interdependence domains since it has mostly been used for information technology systems analysis, planning and development. Practically, our framework presents a tool for practitioners in DBEs to assess and respond to social impact of interdependencies. With this tool, practitioners can make decision on which interdependencies to revise or maintain to improve value co-creation in a DBE. Our study is limited by the sole focus on social impact assessment. Thus, future studies may add other assessment dimensions such as operational and strategic aspects to present a complete evaluation method. Also, our study is limited to one-to-one interdependencies. Future studies can investigate one-to-many or many to many interdependencies. 


\section{References}

1. Bailey, D.E. et al.: Minding the Gaps: Understanding Technology Interdependence and Coordination in Knowledge Work. Organ. Sci. 21, 3, 714-730 (2010).

2. Crowston, K.: Process as theory in information systems research. In: Baskerville, R. et al. (eds.) Organizational and Social Perspectives on Information Technology. pp. 149-164 Springer (2000).

3. Hall, E.: The silient language. Doubleday And Company, New York (1959).

4. Korpela, K. et al.: Digital Supply Chain Transformation toward Blockchain Integration. In: Hawaii International Conference on System Sciences. pp. 4182-4191 (2017).

5. Lenox, M.J. et al.: Does interdependency affect firm and industry profitability? An empirical test. Strateg. Manag. J. 31, 2, 121-139 (2010).

6. Liu, K. et al.: Modelling complex systems for project planning: a semiotics motivated method. Int. J. Gen. Syst. 35, 3, 313-327 (2006).

7. Nachira, F. et al.: A network of digital business ecosystems for Europe: roots,processes and perspectives. In: Digital Business Ecosystem. European Commission Information Society and Media (2007).

8. Pentland, B.T. et al.: A thermometer for interdependence: Exploring patterns of interdependence using networks of affordances. In: International Conference on Information Systems. , Fort Worth (2015).

9. Selander, L. et al.: Capability search and redeem across digital ecosystems. J. Inf. Technol. 28, 3, 183-197 (2013).

10. Senyo, P.K. et al.: Evolution of norms in the emergence of digital business ecosystems. In: Baranauskas, M. et al. (eds.) Socially Aware Organisations and Technologies. Impact and Challenges. pp. 79-84 Springer, Cham (2016).

11. Stamper, R.: Information in business and administrative systems. Batsford, London (1973).

12. Stanley, J., Briscoe, G.: The ABC of Digital Business Ecosystems. Commun. Law - J. Comput. Media Telecommun. Law. 15, 1, 1-24 (2010).

13. Sun, L. et al.: Evaluating business value of IT towards optimisation of the application portfolio. Enterp. Inf. Syst. 10, 4, 378-399 (2016).

14. Tan, F. et al.: Towards a Self-Organizing Digital Business Ecosystem: Examining ITEnabled Boundary Spanning Practice of China's LeEco. In: International conference on Information Systems. pp. 1-12, Dublin, Ireland (2016).

15. Tiwana, A.: Evolutionary Competition in Platform Ecosystems. Inf. Syst. Res. 26, 2, 266281 (2015). 